\title{
Families: Influences in Children's Development and Behaviour, From Parents and Teachers' Point of View
}

\author{
Cláudia Rodrigues Sequeira de Figueiredo, Filomena Valadão Dias \\ Instituto Universitário de Psicologia Aplicada (IU); Research Unit in Psychology and Health (UIPES), Lisboa, Portugal
}

Family plays a very important role in infant's development and behaviour, being that the parents' divorce can be a very stressful experience. This is an exploratory and comparative study that aims at identifying the differences in children's behaviour with divorced parents (or separated) and married parents (or living together), based on the parents and the teachers' perceptions. The authors recruited a convenience sample of 62 children (30 with single parents, and 32 children with married parents) between six and nine years old. To evaluate the parents' perceptions about their children's behaviour, the Portuguese versions of the CBCL (Child Behaviour Check List) and the TRF (Teacher Report Form) for the teachers' perceptions were used. According to the results obtained, teachers indicate single parents' children as having more behavioural problems in two different dimensions than children with married parents; single parents' children without siblings are pointed out as having more behavioural problems than the ones who do not, by their parents and the more spaced the visits of the father are, in single parents' children, more behavioural problems they have, according to the mothers. Therefore, based on our results, teachers and parents indicate that divorce has a negative impact on children's behaviours.

Keywords: family, divorce, infant's development, behaviour

\section{Introduction}

Portugal was the country registering the highest number of divorces in the period between 1995 and 2004 among the 15 countries in Europe, divorces rising from 12,322 to 23,348, what means a rage around 89.4\%. However, it does not mean that in Portugal people get more divorced than in other European countries, on the other hand, according to data from Eurostat (European Statistical Office), the divorce rate in northern EU (European Union) reached $0.6 \%$ while in Portugal the rate was $0.3 \%$ (Carneiro, 2006).

In the 1970s, divorce was recognized legally in Portugal and from that point on the divorce rate has been increasing: between 1975 and 1979, the average of divorces per year stood at 4,794 cases, in the 1980s, the divorce rate increases per year to 7,947 and in the 1990s divorces grew to 13,093 per year. In 2000/2001, the divorce rate has continued to increase $(19,173)$ (National Institute of Statistics, 2001).

Since divorce has become more common in societies, many authors showed interest in this phenomenon and the consequences of it in the family. Therefore, it may be pertinent to pay especially attention to any behaviour changes in children who are undergoing throw this change (parents' divorce) and identify them so

Cláudia Rodrigues Sequeira de Figueiredo, Master, Instituto Universitário de Psicologia Aplicada (IU); Research Unit in Psychology and Health (UIPES).

Filomena Valadão Dias, Master, Instituto Universitário de Psicologia Aplicada (IU); Research Unit in Psychology and Health (UIPES). 
that we can act immediately. In 1991, Amato and Keith examined 92 studies that compared the well-being of children whose parents had divorced with children whose parents were married to each other. This analysis and other studies in the 1990s came to the conclusion that children of divorced parents had lower results with regard to self-concept (Wenk, Hardesty, Morgan, \& Blair, 1994, as cited in Amato, 2000), academic achievement (Astone \& McLanahan, 1991; Teachman, Paasch, \& Carver, 1996, as cited in Amato, 2000), some behavioural problems (Doherty \& Needle, 1991; Simons \& Associates, 1996, as cited in Amato, 2000), the adaptability (Forehand, Neighbors, Devine, \& Armistead, 1994; Kurdek, Fine, \& Sinclair, 1994, as cited in Amato, 2000), and health in the long run (Tucker et al., 1997, as cited in Amato, 2000).

Given that divorce is still a recent phenomenon, it is normal that the solutions and the adaptation of mentalities to the reality of divorce are not the best and most suitable to serve the best interests of the family (Ribeiro, 2007).

\section{Family}

Recent research about family defines its concept as a privileged environment of personality formation and bounding, therefore, it has a fundamental role in the development of toddlers and adolescents (Berry, Kagitçibasi, Georgas, Poortinga, \& Van de Vijler, 2006; Relvas \& Vaz, 2007).

The concept of family has been changing and suffering some important evolution concerning to sexual differentiation, biological factors, and the function of men and women at the symbolic and prohibitions. All of these matter the social evolution. These changings are going to have repercutions in the family structure as well as in its functioning (Bayle, 2005). During a long time, the child occupied a periferic place in the family. However, as time goes by, the child becomes central in the family life (Leal, 2005).

From the systemic theory, perspective family is a part of other contexts and systems which insert in cultural and communitarian contexts that affect the family behaviour (Relvas, 1996; Shaffer, 2005). The family is composed by small units, being the smallest the individual (Relvas, 1996).

Family is a permeable system that is influenced by the context that suffers some variations with the level of family organization. Each family as a specific dynamism gives it a particular autonomy and individuality. Therefore, parents influence their children and children also influence their parents' behaviour and educational practices. The family dynamic also changes with its members' evolution (Shaffer, 2005). That said, if we want to know someone is a mother or a father, we have to observe them in the familiar dynamic (Relvas, 1996).

Some researchers pointed out that the most important role of the families is to transmit a social self. It is within the family that children have their first relationship experiences, therefore, family has a very important role in their children's social development (Thomson, 1998, as cited in Laible, Carlo, Torquati, \& Ontai, 2004; Jackson \& Leonetti, 2001).

\section{Children's Behaviour and Development}

Nowadays, there is a huge worry concerning the development and behaviour of children. Many authors studied this matter and we will briefly address some of these theories in which family play an important role.

From a global perspective, children between six and 10 years old (the age of our sample) are in a consolidation face concerning the learnings acquired in the first childhood, preparing for adolescence. Around the age of six a great cognitive change happens, the child begins to understand the world around him/her, gaining skills to resolve problems, finding new solutions, learning to reflect, judge, and understand that others have a different point of view and that it can bring consequences to them and to the interaction between them. 
At this age, the child's life is pronounced by tensions between the child's autonomy and expectations that can or cannot stimulate his/her self-esteem (Eccles, 1999).

Another important factor at this age is the beginning of school life. At this age, the child enters the preschool and starts spending more time at school and in other activities than with their parents, being also influenced by those who are at school (e.g., teacher and other children) (Eccles, 1999).

Family role taken by some authors (Thomson, 1998, as cited in Laible et al., 2004; Jackson \& Leonetti, 2001; Shaffer, 2005) has the primary agent of socialization, because it is within the family that children began to acquire values, attitudes, and behaviours accepted by society. Therefore, the socialization process has a way of children to learn beliefs, values, and social accepted behaviour (Shaffer, 2005; Laible et al., 2004). It is within the family and in their intern relations that the child learns the basic rules of socialization, the values and duties, being the future behaviours and attitudes conciliated by this intern learning (Mead, 1970; Parsons, 1971; Michel, 1983; Sullerot, 1993; Strauss, 1997; Ginn \& Arber, 1999, as cited in Relvas \& Vaz, 2007).

The experiences within the family are unique and make the relationship with parents and other family members critical to the child's social development (Thompson, 1998, as cited in Laible et al., 2004). Once, the child is born, a process of individual development starts within the family through learning habits, values, and language codes that make the child unique, different from all others. Therefore, the family context plays a fundamental role in the personality development of children and adolescents (Ribeiro, 2007; Relvas \& Vaz, 2007).

In short, it is through learning within the family and parenting, that the child develops socially and psychologically (Vaz \& Relvas, 2007). The reality of family interactions can help the child to prepare himself/herself for the reality outside the family (Jackson \& Leonetti, 2001).

In the Brofenbrenner's perspective, the child has an active and passive role in its development as this model emphasizes the importance of relationships among individuals and changes environments, leading to qualitative changes. Personal or environmental events (e.g., parental divorce) can lead to sudden qualitative changes. This is the theory of ecological systems, which describes the multiple levels of the environment that influence the development of children and adolescents, a number of structures embedded in each other. There are four structures: (1) the micro-system that refers to the activities and interactions that occur in the immediate environment of the person and that gradually becomes more complex as the children come into contact with other contexts (day-care schools), of which family is always part of; (2) the meso-system that consists in the connections or interrelations among micro-systems such as school and pears; (3) the exo-system which includes the contexts in which children and adolescents are not part of but still exert some influence in their development (e.g., parents' working environment); and (4) the macro-system, the cultural context in which the micro-, meso-, and exo- system are embedded. These contexts differ from culture to culture and influence the types of experiences that children have in home and school (Shaffer, 2005).

According to the social learning theory of Bandura (1971) and Bandura and Walters (1963, as cited in Mack, 2001), children learn to behave by observing the behaviour of their attachment figures, shaping up to these behaviours and imitating them. Children build their internal models from the relationships with their caregivers' figures. These internal models are representations of the self, attachment figures, and relationships that have been conceptualized as cognitive-affective filters that will influence how children respond to the other and how they see themselves in the social world (Bretherton, 1990, as cited in Laible et al., 2004). 


\section{Divorce}

Nowadays, one in four children will have to face their parents' divorce and one in 10 children live with only one of them, usually the mother. For all families, the divorce can trigger a series of changes potentially stressful for each member. The child and family tasks where before guided by two parents, now are responsibility of one, such as family roles and functioning can become chaotic. In the preceding months to divorce, many families face financial problems that could result in changes of home, school, and job (Ribeiro, 2007).

According to Souza (2000) and Ribeiro (2007), divorce is not a situation that happens from one day to another, is a complex process that involves multiple changes. Before it happens, it has a lot of history behind, which probably causes the child pain and suffering. A divorce is one of the major stresses that a child can experience as threatening and destabilizing situation that it is being expected that the child's reactions are intense and sometimes lasting (Ribeiro, 2007). In these situations, children can express their confusion, anger, and resentment through aggressive behaviour and being demanding and uncooperative (Hetherington \& Stanley-Hagan, 1995).

The divorce can initiate stressful factors that may negatively influence child and adult, with regard to behaviours, emotions, and physical state. The duration and severity of these effects vary from person to person also depending on the presence of moderators or protection factors (viz., personality traits, the significance of the divorce in the culture in which it is inserted, a good social network, having siblings and grandparents close by, among others). Within this model there are two others: (1) the model of crisis, which sees divorce as a disturbance, to which all individuals eventually adapt over time and is determined by protective factors; and (2) the model of chronic tension which argues that during the divorce there are persistent and enduring tensions that affect the welfare of the child and adult. In this model, the protective factors determine the level of stress felt by the individual (Amato, 2000).

Another model about divorce (Kalter, 1987, as cited in King, 2001) says that the impact of divorce is around two components of development, one concerning the child, the other the course of the divorce process. This author argued that divorce can potentially interfere in three areas of child's development: The first is the ability to modulate the aggression, the child's feelings of pain generated by the absence of a parent, defending himself/herself with anger and aggression; the second is the ability of children to separate themselves emotionally from their parents. The psychological and emotional acceptance at home is essential to the independence and security to feel safe to leave the house. Parents serve as a bridge to independence and autonomy. In cases of single parenthood children usually feel less confident and safe to take this step; the third concerns to the identity, a divorce with a consequent lack of a male figure "produces" a gap in the male model of gender identification in boys. Girls may feel abandoned and rejected and feel her feminine model, the mother, and also rejected. Some studies indicate that many girls from divorced families have more difficulties in adult heterosexual relationships (Wallerstein, 1985, as cited in King, 2001) with more negative attitudes and conflict with their parents (Hetherington, 1972, as cited in King, 2001), marry younger and have negative perceptions about fathers, husbands, and men in general (Hetherington, 1977, as cited in King, 2001).

The family (father and mother) is the foundation to healthy child's development, through them, the children achieve a sense of belonging, stability, and security. A break in the marital relationship increases the risk of social problems, substance abuse, and academic decline (Blankenhorn, 1995; Glenn, 1996; Popenoe, 
1996, as cited in Amato, 2000). On the other hand, other authors argued that the healthy development of the child can occur in a large variety of family structures. From this perspective, the divorce is a second chance for adults to be happy and a solution for children to a dysfunctional family environment (Coontz, 1992; Demo, 1992; Skolnick, 1991; Stacey, 1996, as cited in Amato, 2000).

A study by Pett, Wampold, Turner, and Vaughan-Cole (1999, as cited in Woosley, Dennis, Robertson, \& Goldstein, 2009) concluded that children of divorced parents had more problems in school than those whose parents were still together. However, according to a study by Souza (2000), the initial negative reactions to divorce do not necessarily reflect a long-term commitment, which may indicate that these are just normal reactions to the situation.

There are other factors related to divorce that may also influence the child: moving house, financial problems, losing contact with old friends (changes in his social network), less contact with the father who left home, and/or other members of family and changes in the relationship with the parent who is living (Woosley, Dennis, Robertson, \& Goldstein, 2009).

In this context, there are some factors that can influence the development and behaviour of children that are facing their parents' divorce, such as the quality of the family relationship, depending on how both parents will express and manage it (Ribeiro, 2007). Several studies indicate that through the quality of the relationship with the parents we can predict the behaviour and welfare of the child (Amato, 2000; Love, n.d., as cited in Woosley et al., 2009). A child's personality is also a key factor. Children have different personalities and characteristics, therefore, the impact of divorce is also different for each one of them (Ribeiro, 2007). It is essential existence and involvement with other sources of affection and security (e.g., grandparents, siblings, friends, teachers, and psychologists). These are indeed protection factors that can help the child to adapt better to his/her new situation (Sandler, Tein, \& West, 1994, as cited in Amato, 2000).

School also plays a very important role because that is where the child spends most of his/her time. The teacher can have a major impact on these children during the divorce (Ribeiro, 2007).

Teachers tend to identify more externalizing problems, e.g., aggressive behaviour, and are more alert to behavioural changes in the skills "used" in the classroom, such as attention and concentration. Moreover, parents are more sensitive to problems of internalizing nature, e.g., anxiety and depression (Araújo, 2010), as they share intimate moments.

In summary, the main objective of this research is to compare the behaviours of children from intact families with the behaviours of children in divorced parents. More specifically, we want to: (1) compare the behaviour of children with divorced parents and children with intact families; (2) compare the behaviour of children with divorced parents, depending on the existence of siblings; and (3) compare the behaviour of divorced parents' children, as the frequency of visits of the parent who left home.

\section{Method}

\section{Participants}

The sample was recruited in three private schools in the Lisbon area. Sixty-two children with a range of age between six and nine years old were selected, 32 of them are girls and 30 boys. From the 62 children, 32 have married parents and 30 divorced parents. The average age in both groups was seven. There were 16 boys and 16 girls in the group with married parents, and 14 boys and 16 girls with divorced parents. 


\section{Procedure}

Firstly, study specifications: Goals and tools were presented to the school directors in order to get their approval and later explain to parents and teachers the purpose of this study. Once, the sample needed for the process was sorted and all the agreement forms gathered from school and parents, the forms to be filled up were given by the teachers to the children, who would then pass them to their parents. In the envelope could also be found information concerning the confidentiality of the program, thus, everyone could follow up the whole process. The data were collected between December 2009 and October 2010.

To evaluate the parents' perceptions about their children's behavior, the Portuguese version of the CBCL (Child Behaviour Check List) (Achenbach \& Eldebrock, 1983; Achenbach, 1991), and the TRF (Teacher Report Form) for the teachers' perceptions (Achenbach \& Eldebrock, 1984; Achenbach, 1991) were used.

\section{Instruments}

Both checklists behaviour used in the investigation were part of the Achenbach ASEBA, which is a collection of instruments to measure syndromes.

The CBCL created by Achenbach and Edelbrock (1983) and Achenbach (1991) was used to measure the Portuguese population in 1994 by António Castro Fonseca, António Simões, José Augusto Rebelo, Joaquim Armando Ferreira e Francisco Cardoso (Fonseca, Simões, Rebelo, Ferreira, \& Cardoso, 1994). This checklist has been used for the last six months by parents or caregivers, who are concern by their children inadequate behaviour (Gonçalves \& Simões, 2000).

CBCL can be answered by parents with children between four and 18 years old, there are different versions according to the age (Gonçalves \& Simões, 2000).

This checklist has 113 items randomly distributed involving nine different dimensions (subscales) related to infant syndromes, with Cronbach's alpha quite high in almost all of them: opposition/immaturity (0.82), aggression (0.83), attention problems/hyperactivity disorder (0.77), depression (0.79), social problems (0.53), somatic complains (0.73), isolation (0.66), anxiety (0.65), and obsessive schizoid (0.61). Achenbach (1991) also performed factor analyses of these second-order dimensions that allowed extraction of two factors: the externalizing and internalizing factor. The externalizing factor corresponds to types of behaviour with its problematic focus on relations with others (e.g., aggression). Internalization factor refers to types of behaviour in which the problems are focused on the child itself (e.g., depression) (Gonçalves \& Simões, 2000).

The answers are given on a scale of $0-2$, where " 0 " is "Not true", " 1 ' is "Sometimes true", and " 2 " is "Very often true" (Fonseca et al., 1994).

The status of this inventory is accomplished by the sum of the number of items in each subscale that allows creating a profile of each child, being 70 the cut-off point, the 98th percentile, the border point between normative and clinical populations (Gonçalves \& Simões, 2000).

The TRF of Achenbach and Edelbrock (1984), also a checklist, is similar to the CBCL translated to Portuguese by Fonseca et al. (1995). This inventory gives teacher's observation of the student's behaviour at school. The English version of this inventory is intended for children and adolescents aged between six and 18 years old and it has nine dimensions or subscales: aggressive behaviours, anxiety and depression, behaviour delinquency, somatic complaints, thought problems, attention problems, social problems, social isolation, and other problems. The answers are given from 0 to 2, where "0" corresponds to "Not true", "1" to "Sometimes true", and "2" to "Often true" (Gonçalves \& Simões, 2000). 
Notice that these two surveys are complementary to one another and allow a more complete reading of data, since the items 112,113 , and 118 are common to both; it allows a more detailed analysis of each dimension (Gonçalves \& Simões, 2000).

The questionnaire sample characterization was drawn up to collect some socio-demographic and environmental characteristics of the sample.

\section{Results}

The 16 were tested to normality through "Kolmogorov-Smirnov" since the sample was superior to 50 . Since the value of $p$ ( $p$-value) of all sizes was lower than $\alpha=0.05$, the hypothesis is rejected, so the distribution does not follow a normal distribution with $\alpha=0.05$. Therefore subsequent analyses were performed using the nonparametric Wilcoxon-Mann-Whitney test, based on the medians.

Statistical analysis was performed using the software PASW (Statistics Predictive Analytics Software) (v. 18, SPSS (Statistical Package for the Social Sciences) Inc. Chicago, IL) (Maroco, 2010).

Table 1

Wilcoxon-Mann-Whitney Test Concerning to Differences Between the Behaviours of Children as Their Family Structure

\begin{tabular}{lllll}
\hline & \multicolumn{3}{c}{ Test statistics $^{\mathrm{a}}$} \\
\cline { 2 - 5 } & Mann-Whitney U & Wilcoxon W & $\mathrm{Z}$ & Asymp. Sig. (2-tailed) \\
\hline Opposition and immaturity CBCL & 476 & 941 & -0.057 & 0.955 \\
Aggressive behaviour CBCL & 443.5 & 971.5 & -0.526 & 0.599 \\
Hyperactivity attention CBCL & 406.5 & 934.5 & -1.05 & 0.294 \\
Depression CBCL & 421.5 & 949.5 & -0.942 & 0.346 \\
Social problems CBCL & 439.5 & 845.5 & -0.13 & 0.897 \\
Somatic complaints CBCL & 395 & 860 & -1.352 & 0.176 \\
Withdraw CBCL & 460 & 925 & -0.286 & 0.775 \\
Anxiety CBCL & 451 & 979 & -0.193 & 0.847 \\
Obsessive schizoid CBCL & 381.5 & 909.5 & -1.208 & 0.227 \\
Withdraw TRF & 345.5 & 873.5 & -1.953 & 0.051 \\
Somatic complaints TRF & 437.5 & 965.5 & -0.868 & 0.385 \\
Anxiety depression TRF & 362.5 & 890.5 & -1.684 & 0.092 \\
Social problems TRF & 372 & 900 & -1.607 & 0.108 \\
Thought problems TRF & 401 & 929 & -2.026 & 0.043 \\
Attention problems TRF & 429 & 835 & -0.076 & 0.939 \\
Delinquency behaviours TRF & 338 & 866 & -2.416 & 0.016 \\
Aggressive behaviours TRF & 439 & 904 & -0.165 & 0.869 \\
\hline
\end{tabular}

Note. ${ }^{\text {a }}$ Grouping variable: Divorced_Q_0P5.

Concerning to the main objective of this study, there were found significant differences between the behaviours of children as their family structure in two dimensions: thought problems and delinquency behaviours (TRF) $(\alpha=0.05)$ (see Table 1). However, this analysis was not sufficient to determine whether these behavioural differences were more significant in a group or in another, so we made a descriptive analysis. Although the analysis of Wilcoxon-Mann-Whitney is based on medians and on the following case it was 0 , we looked at the averages.

As shown in the analysis of Table 2, the mean of the children with divorced parents is superior in the both 
dimensions mentioned above, when compared with the mean of children from intact families. This indicates that children with divorced parents are identified by teachers as having more problems at the level of thought and delinquency than children from intact families.

Table 2

Means and Medians of Thought Problems (TRF) and Delinquency problems (TRF)

\begin{tabular}{lll}
\hline & Thought problem (TRF) & Delinquency problem (TRF) \\
\hline Children with married parents & Mean $=0.1250$ & Mean $=0.3125$ \\
Children with divorced parents & Mean $=0.4666$ & Mean $=1$ \\
\hline
\end{tabular}

Table 3

Wilcoxon-Mann-Whitney Test Concerning to the Behaviour Among Children With Divorced Parents Depending on the Existence of Siblings

\begin{tabular}{|c|c|c|c|c|c|}
\hline & Mann-Whitney U & Wilcoxon W & $\mathrm{Z}$ & $\begin{array}{l}\text { Asymp. Sig. } \\
\text { (2-tailed) }\end{array}$ & $\begin{array}{l}\text { Exact Sig. } \\
{[2 \times(1 \text {-tailed }} \\
\text { Sig. })]\end{array}$ \\
\hline Opposition and immaturity CBCL & 96 & 232 & -0.671 & 0.502 & $0.525^{\mathrm{a}}$ \\
\hline Aggressive behaviours CBCL & 97 & 202 & -0.636 & 0.525 & $0.552^{\mathrm{a}}$ \\
\hline Hyperactivity attention CBCL & 89 & 225 & -0.973 & 0.331 & $0.355^{\mathrm{a}}$ \\
\hline Depression CBCL & 67 & 203 & -2.119 & 0.034 & $0.064^{\mathrm{a}}$ \\
\hline Social problems CBCL & 67 & 203 & -1.934 & 0.053 & $0.064^{\mathrm{a}}$ \\
\hline Somatic complaints CBCL & 76 & 212 & -1.785 & 0.074 & $0.142^{\mathrm{a}}$ \\
\hline Withdraw CBCL & 56 & 192 & -2.359 & 0.018 & $0.019^{\mathrm{a}}$ \\
\hline Anxiety CBCL & 73.5 & 209.5 & -1.651 & 0.099 & $0.110^{\mathrm{a}}$ \\
\hline Obsessive schizoid CBCL & 58 & 194 & -2.28 & 0.023 & $0.025^{\mathrm{a}}$ \\
\hline Withdraw TRF & 74 & 210 & -1.604 & 0.109 & $0.120^{\mathrm{a}}$ \\
\hline Somatic complaints TRF & 89 & 225 & -1.29 & 0.197 & $0.355^{\mathrm{a}}$ \\
\hline Anxiety depression TRF & 89 & 225 & -0.965 & 0.335 & $0.355^{\mathrm{a}}$ \\
\hline Social problems TRF & 111.5 & 216.5 & -0.021 & 0.983 & $0.984^{\mathrm{a}}$ \\
\hline Thought problems TRF & 98 & 234 & -0.833 & 0.405 & $0.580^{\mathrm{a}}$ \\
\hline Attention problems TRF & 107.5 & 212.5 & -0.189 & 0.85 & $0.854^{\mathrm{a}}$ \\
\hline Delinquency behaviours TRF & 75.5 & 211.5 & -1.657 & 0.098 & $0.131^{\mathrm{a}}$ \\
\hline Aggressive behaviours TRF & 112 & 217 & 0 & 1 & $1.000^{\mathrm{a}}$ \\
\hline Other problems TRF & 110.5 & 246.5 & -0.064 & 0.949 & $0.951^{\mathrm{a}}$ \\
\hline
\end{tabular}

Notes. ${ }^{\text {a }}$ Not corrected for ties.

Concerning to the second hypothesis, significant differences were found in the dimensions of social problems, withdraw, obsessive behaviours - schizoid and depression, identified by the divorced parents. This confirms that there are differences in the behaviour among children with divorced parents, depending on the existence of siblings $(\alpha=0.05)$ (see Table 3 ). In Table 4 , the medians of each dimension are differentiated, where differences were found. The children who have no siblings are identified by the parents in these four dimensions, as having more problems than those who have siblings.

Concerning to the third hypothesis, there are significant differences in one dimension between children with divorced parents, depending on the frequency of visits of the parents who left home (see Table 5). After the analysis of the medians of the dimension opposition/immaturity, it can be concluded that the children who see the parents once a week are identified by parents, as being the ones with the most problems (see Table 6). 
Table 4

Means and Medians of Obsessive Squizoid CBCL With and Without Siblings

\begin{tabular}{|c|c|c|c|c|c|c|c|}
\hline & & \multicolumn{3}{|c|}{ With siblings statistics } & \multicolumn{3}{|c|}{ Without siblings statistics } \\
\hline & & Withdraw CBCL & $\begin{array}{l}\text { Obsessive } \\
\text { Squizoid CBCL }\end{array}$ & $\begin{array}{l}\text { Depression } \\
\text { CBCL }\end{array}$ & $\begin{array}{l}\text { Withdraw } \\
\text { CBCL }\end{array}$ & $\begin{array}{l}\text { Obsessive } \\
\text { Squizoid CBCL }\end{array}$ & $\begin{array}{l}\text { Depression } \\
\text { CBCL }\end{array}$ \\
\hline \multirow{2}{*}{$\mathrm{N}$} & Valid & 16 & 16 & 16 & 14 & 14 & 14 \\
\hline & Missing & 0 & 0 & 0 & 0 & 0 & 0 \\
\hline Mean & & 1.8125 & 1.8125 & 0.625 & 3.7143 & 3.5714 & 2.3571 \\
\hline Median & & 1.5 & 2 & 0 & 3.5 & 4 & 2 \\
\hline
\end{tabular}

Table 5

Wilcoxon-Mann-Whitney Test Concerning to the Behaviour Among Children With Divorced Parents Depending on the Frequency of Visits of the Parents Who Left Home

\begin{tabular}{|c|c|c|c|c|c|}
\hline & \multicolumn{5}{|c|}{ Test statistics ${ }^{\mathrm{b}}$} \\
\hline & Mann-Whitney U & Wilcoxon W & $\mathrm{Z}$ & $\begin{array}{l}\text { Asymp. Sig. } \\
\text { (2-tailed) }\end{array}$ & $\begin{array}{l}\text { Exact Sig. [2× } \\
\text { (1-tailed Sig.)] }\end{array}$ \\
\hline Opposition and immaturity CBCL & 21 & 76 & -1.997 & 0.046 & $0.053^{\mathrm{a}}$ \\
\hline Aggressive behaviours CBCL & 33.5 & 88.5 & -0.962 & 0.336 & $0.356^{\mathrm{a}}$ \\
\hline Hyperactivity attention CBCL & 34 & 89 & -0.923 & 0.356 & $0.400^{\mathrm{a}}$ \\
\hline Depression CBCL & 30 & 85 & -1.328 & 0.184 & $0.243^{\mathrm{a}}$ \\
\hline Social problems CBCL & 37 & 92 & -0.273 & 0.785 & $0.829^{\mathrm{a}}$ \\
\hline Somatic complaints CBCL & 43.5 & 88.5 & -0.142 & 0.887 & $0.905^{\mathrm{a}}$ \\
\hline Withdraw CBCL & 35.5 & 90.5 & -0.788 & 0.431 & $0.447^{\mathrm{a}}$ \\
\hline Anxiety CBCL & 32 & 77 & -0.765 & 0.444 & $0.489^{\mathrm{a}}$ \\
\hline Obsessive schizoid CBCL & 38.5 & 83.5 & -0.179 & 0.858 & $0.863^{\mathrm{a}}$ \\
\hline Withdraw TRF & 41 & 96 & -0.331 & 0.74 & $0.780^{\mathrm{a}}$ \\
\hline Somatic complaints TRF & 41.5 & 96.5 & -0.347 & 0.729 & $0.780^{\mathrm{a}}$ \\
\hline Anxiety depression TRF & 43 & 88 & -0.166 & 0.868 & $0.905^{\mathrm{a}}$ \\
\hline Social problems TRF & 41.5 & 86.5 & -0.293 & 0.769 & $0.780^{\mathrm{a}}$ \\
\hline Thought problems TRF & 31.5 & 76.5 & -1.424 & 0.154 & $0.278^{\mathrm{a}}$ \\
\hline Attention problems TRF & 19.5 & 55.5 & -1.601 & 0.109 & $0.114^{\mathrm{a}}$ \\
\hline Delinquency behaviours TRF & 38.5 & 83.5 & -0.594 & 0.553 & $0.604^{\mathrm{a}}$ \\
\hline Aggressive behaviours TRF & 42 & 87 & -0.249 & 0.804 & $0.842^{\mathrm{a}}$ \\
\hline Other problems TRF & 38.5 & 83.5 & -0.543 & 0.587 & $0.504^{\mathrm{a}}$ \\
\hline
\end{tabular}

Notes. ${ }^{\mathrm{a}}$ Not corrected for ties; ${ }^{\mathrm{b}}$ Grouping variable: Q_0P6.

Table 6

Means and Medians of the Dimension Opposition Immaturity CBCL According to Visits From in Days and Once a Week

\begin{tabular}{|c|c|c|c|}
\hline & & \multicolumn{2}{|c|}{ Opposition immaturity CBCL } \\
\hline & & From 15 in 15 days & Once a week \\
\hline \multirow{2}{*}{$N$} & Valid & 10 & 9 \\
\hline & Missing & 0 & 0 \\
\hline Mean & & 3.9 & 8.444 \\
\hline Median & & 3 & 9 \\
\hline Std. deviation & & 1.9120 & 5.318 \\
\hline Minimum & & 1 & 1 \\
\hline Maximum & & 7 & 17 \\
\hline
\end{tabular}




\section{Discussion}

Concerning the main objective of this research, which is to compare the behaviour of children with divorced parents and children with married parents, it was found that there are differences in behaviour between the groups in two dimensions: thinking and delinquency problems, identified by teachers. Given the results, it is possible to assume that divorce can affect the child's behaviour, as it has been suggested by previous works (Amato \& Keith, 1991; Mack, 2001; Pett, Wampold, Turner, \& Vaughan-Cole, 1999, as cited in Woosley et al., 2009).

Divorce involves multiple stressing factors that may negatively influence the child's behaviour, emotions, and health (Amato, 2000). The obtained results can be enlightened by the perspective that considers divorce as an event that causes pain and suffering in children, as well as feelings of insecurity and fear. Consequently, behaviour changes or problems are expected to happen. Moreover, it would not be common for a child to face parents' divorce, to be apathetic, denying the new family reality. In this situation, the absence of any reaction would be, at least, as concerning as the behaviour problems.

Regarding to the responses of divorced parents and married parents, there was not any difference between the behaviours of children from both groups. As it was said previously, teachers identified more behaviour problems in children from single parent families, a result that is contrary to the literature available. So, it can be admitted that some of the problematic behaviours are only triggered by specific factors or stimulus (e.g., the presence of other peers) and the context (Achenbach \& MacConaughy, 1987, as cited in Silva, 2008). It is also possible that the absence of the parents during school time can induce the behaviours identified by the teachers, and this would explain why parents have not described problematic behaviours, as they do not happen in their presence.

Explaining the differences between the results obtained from parents and from teachers, the Ribeiro's (2007) approach about parents' availability and presence can be helpful. It says that after a complicated divorce, parents may not be capable of being available enough for a child, or of identifying the behaviour problems. The explanations for this are the pain and suffering that the divorce may cause to parents, which makes them less attentive.

Therefore, teachers, as they do not live in the divorce situation as parents do, may be able to better acknowledge the behaviour changes in children. In addition, as children grow they tend to spend more time at school or in other activities after school, than with their parents (Eccles, 1999), so, it increases the possibility of teachers to witness more problematic behaviours than parents.

In this sample, half of the children from a single parent family practice sports or have other leisure activities after school. This shows that these children spend a significant part of their time out of their family environment, and suggests that it is more probable to identify the behaviour changes or the problematic behaviours in the absence of their parents.

Nowadays, there is a growing comprehension and attention of schools to their children, in order to promote children's well-being, not only academic, but also personal and emotional. Thus, it is essential that families and schools work together to help and support children, making it simpler for them to face school and family problems, like divorce.

It can also be assumed that parents' responses are related to social desirability.

However, and summing up, the results cannot be solely explained by the divorce. As it is known, it is not the divorce by itself that jeopardizes children, there are other significant contributors that weaken the child, like 
the setting of the divorce, the existence of parental conflict, and the way how both parents express and manage it (Davies \& Cummings, 1998, as cited in Harold, Shelton, Goeke-Morey, \& Cummings, 2004; Ribeiro, 2007). Nevertheless, the impact of a divorce can never be forgotten. The divorce is one of the most stressful moments that a child can experience, and a situation responsible for causing fear and insecurity.

The family, the father and mother are the fundamental basis for the children's healthy development, because it is among its family that the child feels secure, loved, and protected. The security that exists in parental interactions is critical for the emotional stability of the child (Ribeiro, 2007).

Taking the variable siblings into account, the results show that in single parent families, children with no siblings are identified by their parents as having more behaviour problems than those who have siblings. So, it can be admitted that these results may be related to protection factors mentioned in previous work. These protective factors are helpful for a child to go through a parents' divorce, as they are a source of security and affection (like the support of a brother), and can be important for a child to adapt easily to separation process (Sandler, Tein, \& West, 1994, as cited in Amato, 2000; Ribeiro, 2007).

Sometimes, in situations of divorce, as already mentioned above, when children realize the end of love between their parents, they wonder if the love that their parents feel for them can also end (Ribeiro, 2007). In this context, for example, having another person nearby who is going through the same situation, but who acts as a support reassuring and supporting the child, may have a protective effect that helps the child to overcome and adapt to the new family structure. Having siblings to say that everything is fine, that everything will go in the best way and that both are in the same situation, together, can make a difference. Or even having to be the older sibling to reassure and support the younger brother can also help themselves organizing the thoughts and better understanding their feelings, about their parents' divorce.

So, having siblings and being one can prove to be a facilitator and protective factor to the child's adjustment to divorce. In future, it would be interesting to investigate other variables that may be associated here too, as the child's personality and how the divorce occurred, which can also function as protective and facilitators' agents.

The presence and involvement of grandparents and the practice of activities, such as sports, music, and activity groups (e.g., scouts) are also presented in literature as protective factors that facilitate the divorce process for children (Sandler, Tein, \& West, 1994, as cited in Amato, 2000; Ribeiro, 2007). However, not enough data were obtained that could demonstrate the influence of these variables, because most children belonging to a single parent group engage in some kind of activity and have regular contact with their grandparents, making it impossible to make a comparison.

Last but not least, we are going to look into the importance of the contact with the parent who left home during the divorce, usually the father. Thus, we compared children of a single parent group who saw the parent who left the house on a fortnight basis of 15-to-15 days against those who saw once a week. The reasons why we chose these two frequencies were due to the fact that these were the ones that had a higher frequency response, rather than respond to the hypothesis "Have no contact with the parental figure who left home". Another reason that led to the choice of these two frequencies was that, although not much different in terms of timing, but the quality of the visits makes all the difference see the father fortnight 15-to-15 days or once a week, regardless of the quality of the relationship, in the sense that where before the divorce the child lived with this every day.

Divorce does not necessarily mean loss of contact, relationship, or interaction, because this can happen in 
any family due to specific circumstances (e.g., professional reasons). From the psychological point of view, what matters is not the cohabitation itself, but rather the symbolic order in which the existence of a father and a mother is implied (Leal, 2005).

The results indicate that children who are with the parent who left home once a week exhibit more behaviour problems than those who come from 15-to-15 days.

The results are not supported by the literature that points the absence or abrupt withdrawal of an experience that was once daily as an important factor that can influence the behaviour, conduct, and well-being of the child, accompanied by feelings of insecurity, sadness, fear of loss and abandonment. Before guided by two parents, now he/she is guided only by one and the roles and family structure may be disorienting, confusing and destabilizing the child even more, which can lead to behaviour problems (Ribeiro, 2007).

Adding to the behavioural problems that a child can develop, with a possible absence of a male figure, there is also the possibility of a gap in the male model of gender identification in the case of boys. The girls, in addition to behaviour problems cited above, tend to feel rejected and abandoned. The distance, the absence of the father, or the poor familiarity with him, can make it difficult for the girl to appreciate her femininity and learn feminine behaviours (King, 2001).

Therefore, it would be expected that children who see the father on a fortnight basis (15-to-15 days) were identified as having more behaviour problems than the other group (weekly basis), which did not happen. This difference between the literature and results may be related to the fact that, in this sample, the quality of the relationship between the father (who has left home) and his child has been maintained or even improved, not forgetting the personality characteristics of each child. A child is not a blank sheet of paper where you write what you want and then erase it, he/she has, or is starting to build his/her own personality, defenses, and own understanding of the world around him/her.

Given that most divorces, in this sample, happened two years ago we can also ponder about the possibility that it is still a recent event for the child and that the absence of his/her father in his/her daily routine is still felt regardless of the frequency of the visits.

\section{Conclusion}

The main conclusion of this research is that parents and teachers tend to identify more behaviour problems in divorced families' children than in intact families' children. Divorce is an important variable, nevertheless the impact of family role and welfare is noteworthy for the children's behaviour. To what extent can divorce be an embrittled experience? Due to the uniqueness of each child's characteristics, it is not feasible to make predictions nor future assumptions. Notwithstanding, it is important to ensure the child's safety, protection, and love in the context of here-and-now, through child's divorce perspective regard.

This research is based on multiple informants' perceptions of the children's behaviour. These informants, parents and teachers, participate in different contexts of children's lives. This set of information allows us a more complete and rich overview, hence, enabling a better understanding of the child's behaviour and its conditions and contexts. This information is crucial to make an intervention plan which is complete and tailored to the needs of the child.

\section{Limitations}

To make this research more robust, it would be necessary to take the child's perspective into account, where his/her understanding of the divorce and his/her behaviour is important. 


\section{References}

Achenbach, T., \& McConaughy, S. (2003). The Achenbach system of empirically based assessment (pp. 406-433). In C. Reynolds, \& R. Kamphaus (Eds.), Handbook of psychological \& educational assessment of children-Personality, behaviour and context (2nd ed.). New York: The Guilford Press.

Amato, P. (2000). The consequences of divorce for adults and children. Journal of Marriage and the Family, 62, 1269-1287.

Araújo, L. (2010). Relationship between childhood behavior and social vulnerability in the city of Belo Horizonte-MG (Doctoral dissertation, Institute of Psychology of São Paulo).

Bayle, F. (2005). The parenting. In I. Leal (Ed.), Psychology of pregnancy and parenting (pp. 317-346). Lisbon: Fim de Século.

Berry, J., Kagitcibasi, C., Georgas, J., Poortinga, Y., \& Van de Vijver, F. (2006). Families across cultures: A 30-nation psychological study. Cambridge: Cambridge University Press.

Carneiro, I. (2006). Divorces grew $98 \%$ in ten years. News Journal. Retrieved June, 2010, Retrieved from http://jn.sapo.pt/paginainicial/interior.aspx?content_id=549471

Davies, P., Sturge-Apple, M., Winter, M., Cummings, M., \& Farrell, D. (2006). Child adaptational development in contexts of interparental conflict over time. Child Development, 77, 218-233.

Eccles, J. (1999). The development of children ages 6 to 14. The Future of Children When School Is Out, 9(2), 30-44.

Fonseca, A., Simões, A., Rebelo, J., Ferreira, J., \& Cardoso, F. (1994). An inventory of social skills and behavior problems in children and adolescents. In J. Pais-Ribeiro (2007), Assessment in health psychology: Instruments published in Portuguese (pp. 55-78). Coimbra: Quartet.

Gonçalves, M., \& Simões, M. (2000). The multiaxial model of Achenbach (ASEBA) in clinical assessment of children and adolescents. In I. Soares (Coordinator), Developmental psychopathology: Trajectories (in) adaptive throughout life (pp. 43-87). Coimbra: Quartet.

Harold, G., Shelton, K., Goeke-Morey, M., \& Cummings, M. (2004). Marital conflict, child emotional security about family relationships and child adjustment. USA: Blackwell Publishing.

Hetherington, E., \& Stanley-Hagan, M. (1995). Parenting in divorced and remarried families. In M. Bornstein (Ed.), Handbook of parenting-status and social conditions of parenting (Vol. 3, pp. 233-254). UK: Lawrence Erlbaum Associates, Inc..

King, E. (2001). Children and divorce. In C. Walk, \& M. Roberts (Eds.), Handbook of clinical child psychology (pp. 1031-1042). New York: John Wiley and Sons Inc..

Laible, D., Carlo, G., Torquati, J., \& Ontai, L. (2004). Children's perceptions of family relationships as assessed in a doll story completion task: Links to parenting, social competence, and externalizing behaviour. England: Blackwell Publishing.

Leal, I. (2005). New and old parenthoods. In I. Leal (Ed.), Psychology of pregnancy and parenting (pp. 363-409). Lisbon: End of the Century.

Mack, K. (2001). Childhood family disruptions and adult well-being: The differential effects of divorce and parental death. Death Stud, 25(5), 419-443.

Maroco, J. (2010). Statistical analysis with PASW statistics (ex-SPSS). Pêro Pinheiro.

National Institute of Statistics. (2001). Portugueses: Less marriage? Retrieved June, 2010, from http://alea-estp.ine.pt/html/ actual/html/act33.html

Relvas, A. (1996). The family life cycle-Systemic perspective. Lisbon: Issues Afrontamento.

Relvas, A., \& Vaz, C. (2007). Single parenthood: A family a part or part of the family. In A. Relvas, \& M. Alarcão (Eds.), New forms of family (pp. 253-269). Coimbra: Quartet.

Ribeiro, M. (2007). Children and divorce. Lisbon: Editorial Presence.

Shaffer, D. (2005). Developmental psychology: Childhood and adolescence (pp. 60-64, 536-547). São Paulo: Pioneira Thomson Learning.

Silva, F. (2008). Autonomy behavior in children before entering primary school: Behaviors autonomy and emotional and behavioral disturbance (Master's thesis, Faculty of Psychology and Educational Sciences).

Souza, R. (2000). After mom and dad are separated: A report of the children. Psychology: Theory and Research, 16(3), $202-211$.

Woosley, J., Dennis, C., Robertson, K., \& Goldstein, J. (2009). Perceived psychological well-being of children from divorced and nondivorced families. Psi. Chi. Journal, 14(1). 